Pre-print version. Published (2016) Journal of Pragmatics 95: 120-136.

\title{
“Just kidding": Teasing and claims to non-serious intent
}

\author{
Michael Haugh \\ University of Queensland
}

\begin{abstract}
The analysis of humour in interaction is often closely tied to the intentions of the producer in question. The notion of intent that is invoked in humour research generally involves a deontological construct, where issues of moral accountability come to the fore. In this paper, the role of claims to non-serious intent with respect to (ostensibly) jocular forms of teasing amongst speakers of English are examined in order to broaden our understanding of this deontological account of intent. Building on an analysis of the action-sequential environments in which claims to non-serious intent are made, a distinction is first made between two distinct teasing practices, jocular mockery and jocular pretence. These practices are revealed as distinct through the design of the tease itself (i.e. whether it is delivered as non-serious or serious), the sequential placement of laughter from recipients (i.e. whether it is contiguous with the tease or delayed), and what next action is made contingently relevant by a claim to non-serious intent (i.e. a return to serious talk or laughter). It is subsequently claimed that claims to non-serious intent are not only sequentially implicative, but morally implicative as well, given such claims revolve around the degree to which producers may be legitimately held accountable for the potentially serious implications of the tease in question, and the degree to which recipients are licensed to take offence. The moral work accomplished through claims to non-serious intent include pre-empting or blocking the taking of offence in response to the tease, acknowledging a possible impropriety, sanctioning a recipient for taking things too seriously, and disputing the appositeness of the claim to non-serious intent itself. It is concluded that claiming non-serious intent is sequentially and morally implicative, and so constitutes a situated social action in and of itself, and that an analysis of the interpersonal implications of teasing, including the interactional accomplishment of interpersonal evaluations, participant identities and relationships, requires careful attention be directed accordingly. The implications of this first order, discursive account of intent for technical, second accounts of cognition-for-interaction are also briefly considered.
\end{abstract}

\section{Keywords:}

teasing, humour, jocular mockery, intention, interactional pragmatics, Australian English, American English

\section{Introduction}

Defining humour is a complex and challenging task for researchers (Hatch and Erlich, 1993: 506; Schnurr, 2010). In studying conversational humour, the focus has generally been on identifying various paralinguistic, prosodic and discoursal clues (Holmes, 2000: 163) through which "participant(s) signal amusement to one another" (Mullany, 2004: 21, emphasis added). There is also been a distinction made between intentional humour, on the one hand, which may be either "successful” or "unsuccessful”, and "unintended" humour (Mullany, 2004; see also Bell, 2015). In these ways, then, the analysis of humour in interaction has been closely tied to the intentions of the producer in question.

However, making inferences about the likely or plausible intentions of participants is not an activity that is limited to professional analysts of humour. Participants may also orient to issues of perceived intent when engaging in various forms of conversational humour. It has long been recognised by researchers that inferences about "humorous intent" may well be 
negotiated by participants in the course of interaction (Attardo, 1994: 308). This is a result of the way in which the cues to talk as non-serious may be somewhat ambivalent leading participants to question "is this play? (Bateson, 1955; Sacks, 1972), and the way in which non-serious frames may be "laminated" together with serious frames of interpretation (Goffman, 1979). The phenomenon of teasing and its relationship to humour is a case in point. Teasing is generally understood to involve combining elements of (ostensible) provocation with (ostensible) non-seriousness, including being framed as playful or jocular (Drew, 1987; Haugh, 2014). Yet given the potential for teasing to be construed as aggressive or hostile, a point well noted by social psychologists (e.g. DiCioccio, 2010; Kowalski, 2000; Wright and Roloff, 2013), attributing intentions can prove critical for those participants (Kruger, Gordon and Kuban, 2006). As de Jongste (2013) points out, however, acknowledging that humorous intent can be negotiated leaves somewhat open the question of what do we as scholars of humour actually mean by "intention"?

For the most part it seems a lay or folk sense of intend or intention (Gibbs, 1999: 19-22; Knobe, 2003; Malle, 2004) is being invoked by humour researchers. This leads to a treatment of intended humour as goal-oriented or strategic (i.e. done to achieve something) and deliberate (i.e. done with awareness of the implications of what one is doing or saying) (Holmes, 2000), while unintended humour is regarded as non-deliberate and non-strategic (Mullany, 2004). ${ }^{1}$ It also leads us as analysts to divide humour into instances that are successful (i.e. where the humorous intent of the producer is realised) and unsuccessful (e.g. where the humorous intent of the producer is not recognised, understood, or appreciated) (Hay, 2001). Yet given humour often involves ambiguity or ambivalence with regards to the producer's intentions (Dynel, 2011), participants may legitimately deny any "serious" reading of these intentions, while still allowing serious meanings to be implicated or at least to remain inferable (Attardo, 1994; Bell, 2015; Dynel, 2009, 2011; Haddington, 2011; Kane, Suls and Tedeschi, 1977; Norrick, 1993; Partington, 2006).

While the notion of intention is often linked in pragmatics and beyond with the (perceived) cognitive reality of participants (Wedgewood, 2011), then, in research about conversational humour the focus, albeit largely implicit and unvoiced, has primarily been on intention as a discursive construct, that is, as involving "evaluations by others of the speaker's awareness of the implications of what he is saying or doing, and/or evaluations of what the speaker is aiming to do through the utterance (or behaviour more broadly)" (Haugh, 2012: 168). A discursive perspective conceptualises intention as a deontological construct, where issues of moral accountability, as well as the interactional work that can be accomplished through such moral claims, come to the fore (Edwards, 2008; Haugh, 2008, 2013; Haugh and Jaszczolt, 2012: 109-111). This includes, for instance, attempts to retract serious implications of humour through disclaimers (Kane, Suls and Tedeschi, 1977; Norrick, 1993), or laminating non-seriousness on to a previously serious comment in order to “recontextualise it as ambiguous” (Haddington, 2011; see also Holt, 2013). It thus demands an account of cognition-for-interaction that addresses such dynamics (Arundale, 2008; Deppermann, 2012; de Jongste, 2013; Gibbs, 2012; cf. Levinson, 2006).

Recent studies by Haddington (2011) as well as Skalicky, Berger and Bell (2015) illustrate the kinds of interactional work that can be accomplished through participants signalling non-serious intent. Haddington (2011), for instance, examines the interactional functions of the phrase vitsi vitsi ('joke-joke') in everyday Finnish interactions using conversation analysis. He suggests that the 'joke-joke' expression can be used in teasing and overstatements to: (1) undertake repair, (2) disclaim and disaffiliate from one’s immediately

\footnotetext{
${ }^{1}$ There may, of course, be instances of faux unintended humour, which are ostensibly non-deliberate and thus covertly strategic, and other variations therein, a point touched upon by Bell (2015) when discussing instances of "anti-humour" (p.36).
} 
prior stance in order to retrospectively recontextualise it as ambiguously (non-)serious, and (3) to promote "mutual affiliation and agreement" (p.151). Skalicky, Berger and Bell (2015), on the hand, identified and coded four key functions of "just kidding" and related expressions, drawing from a corpus-assisted analysis of 1200 instances of such expressions in humorous interactions amongst American speakers of English. These included (1) "inoculation", the pre-emptive use of disclaimers to forestall negative reactions (2) "repair of failed humour" through "naming" the prior utterance as a joke subsequent to an attempt at humour or play not being recognised, understood, or appreciated, (3) making a bid to "return to serious”, that is, a return to a serious or non-playful frame of talk subsequent to a joking sequence, and (4) "setting up new joke", that is, subverting the expectations of other participants through use of disclaimers to launch extensions of the previous joke (Skalicky, Berger and Bell 2015: 23-27). While the most commonly coded function was found to be preemptive use of the disclaimer, they argued that such expressions can serve multiple pragmatic functions.

Both of these studies nicely illustrate that the interactional work accomplished by claims to non-serious intent goes beyond simply repairing misunderstood or unappreciated humour. What is less readily apparent, however, is the way in which such disavowals or disclaimers actually accomplish "mutual affiliation and agreement” (Haddington, 2011: 151), or “inoculate the speaker against any negative reaction” (Skalicky, Berger and Bell 2015: 23), in the first place. Such an account, it is suggested here, requires us to consider the inherently moral nature of claims to non-serious intent, and how this underpinning morality intersects with the different forms of humour that may be involved in such episodes.

The aim of this paper is thus to build on these prior analyses in further exploring the role of claims to non-serious intent with respect to (ostensibly) jocular forms of teasing amongst speakers of English. Drawing from close interactional analysis of a collection of instances where the expressions "just kidding”, "only joking” and variants therein occurred in teasing sequences, it is argued that claiming non-serious intent constitutes a form of locally situated social action. After first describing, in section two, the methods employed and the dataset in question, the role of such expressions with respect to two different forms of jocular teasing, (1) other-directed jocular mockery (Haugh, 2010, 2014) and (2) jocular pretence, are briefly outlined in section three. It is next argued, in section four, that claiming non-serious intent is sequentially and morally implicative, and thus constitutes a situated social action in and of itself. The implications of this for the analysis of interpersonal dimensions of jocular forms of teasing, along with issues of cognitive ascription, are then briefly discussed in the conclusion.

\section{Data and method}

A collection of 33 candidate tokens where participants employed an expression of the form “([I/he/she] [am/was] [just/only]) [kidding/joking]” was first assembled from a range of different corpora of spoken interaction amongst American and Australian speakers of English. ${ }^{2}$ Given its relatively low frequency in naturally occurring spoken interaction (Skalicky, Berger and Bell, 2015: 21), a search for such expressions was undertaken across a number of different datasets where both transcripts and audio(visual) recordings are available, including 46 conversations from the Corpus of Australians and Americans Talking (CAAT), 100 conversations from the Australian component of the International Corpus of English (ICE-AUS), 27 recordings of talkback radio shows from the Australian Radio

\footnotetext{
2 There may well be subtle differences in the semantics of joking and kidding, including across different national and regional varieties of English, but a consideration of these lies outside the scope of this paper. For the record, however, 6 tokens were used by 6 different Australian participants ("kidding” = 3; “joking” = 3), while 27 tokens were used by 19 different American participants ("kidding” = 20; “joking” = 7).
} 
Talkback corpus (ART), 30 conversations from the CallFriend EnglishNorthern Corpus (CallFriend Engn), 10 conversations from the CallFriend EnglishSouthern Corpus (CallFriend Engs), 120 conversations from the CallHome Corpus (CallHome), and 60 conversations from the Santa Barbara Corpus of Spoken American English (SBCSAE). ${ }^{3}$ The 31 surrounding sequences in which these 33 candidate tokens appeared were transcribed using standard CA conventions (Jefferson, 2004a).

The candidate collection of sequences containing the expressions were then analysed within an interactional pragmatics framework (Arundale, 2010; Haugh, 2012, 2015a), namely, an approach to the analysis of pragmatic phenomena that is informed by research and methods in ethnomethodological conversation analysis. The main focus of this analysis was on carefully examining the action-sequential environments in which claims to non-serious intent are made. The analysis focused on the actual recordings themselves, not only the associated transcripts. This involved close examination of both turn design and responses to prior turns. The former arguably affords the analyst insight into inferences available to participants that are licensed by the compositional and sequential design of those turns (Drew, 2013; Schegloff, 2007), while the latter enables the analyst to warrant his or her inferences about how participants have understood the just prior turn (Heritage 1984a). It is important to note, however, that in this approach although the inferences of the analyst are licensed by close examination of the interactional details of the talk, they are, of course, defeasible, just like all pragmatic inferences (Culpeper and Haugh, 2014).

From this preliminary analysis it emerged that 27 tokens occurred in sequences involving some form of other-directed teasing, 4 tokens were in sequences involving self-directed or third-party directed mockery, and 2 tokens occurred within instances of reported speech. The 27 tokens that occurred in teasing sequences were then more closely examined, revealing two distinct practices, namely, jocular mockery and jocular pretence. These two teasing practices, and the role played by claims to non-serious intent with respect to them, are discussed in more detail in the following section.

\section{Claims to non-serious intent in teasing episodes}

Teasing is generally understood to involve combining elements of (ostensible) provocation with (ostensible) non-seriousness. It thus encompasses a heterogeneous class of phenomena (Haugh, forthcoming b), ranging from jocular mockery (Haugh, 2010, 2014), to playful jousting (Decapua and Boxer, 1999), goading (Mitchell, 2015), and baiting (Beach and Dunning, 1982), through to sexual teases (Alberts, 1992; Hopper, 1995). Pawluk (1989) suggests that the multiple lay senses ascribed to teasing in English arise from two basic etymological roots. The first is the Anglo-Saxon notion of tósan. This originally meant "to tear to pieces" to "to pull to pieces", but by the early $17^{\text {th }}$ century had developed the figurative sense of cutting down of the recipient, in part through its conflation with the Scots term heckle. The second etymological root of teasing is the Anglo-Norman term (at)tiser (from Latin attitiare), which literally means to "stir up a fire (or furnace)", but is used figuratively to mean to "stir up emotions", and thus involves a figurative setting up of the recipient in English.

\footnotetext{
${ }^{3}$ CAAT was collected through the support of a Discovery grant from the Australian Research Council (DP120100516). The excerpts from CAAT discussed in this paper are accessible to readers through the online version of this paper. The transcripts for both ICE-AUS and ART are available through the Australian National Corpus (http://www.ausnc.org.au). The author would like to thank Pam Peters at Macquarie University for allowing access to the audio recordings associated with these transcripts. Finally, the audio files and transcripts for CallFriend, CallHome and SBCSAE are available through Talkbank (http://www.talkbank.org).
} 
Close examination of the candidate collection of other-directed teasing sequences revealed two distinct teasing practices, jocular mockery, which involves a figurative cutting down of the target, and jocular pretence, which involves a figurative setting up of the target. Overall, 12 tokens of “just kidding”, “only joking” and other variants were found in 12 sequences involving jocular mockery, while 15 tokens of these expressions were found in 13 sequences involving jocular pretence. In this section, these two practices are each discussed in turn.

\subsection{Jocular mockery}

The first form of jocular teasing where claims to non-serious arose involved what has previously been termed other-directed jocular mockery (Haugh, 2010, 2014). Jocular mockery is a form of teasing where speakers figuratively cut down or diminish the target in some way, but do so within a non-serious or playful frame. These instances of mockery were construed as jocular through various cues to non-seriousness in the delivery of the mocking remark itself, and through laughing responses on the part of recipients (see Haugh [2014: 7882] for further discussion of design and response features of jocular mockery). The general pattern involved jocular cues that were immanent to the design of the tease, followed by contiguous laughter by recipient(s) in next turn. ${ }^{4}$

In the following excerpt from a conversation between two Australians getting acquainted, for instance, mockery is occasioned when Paula (who is female) tells Tim that she was the "best man" at the wedding of a mutual friend. She herself laughs at this and claims it to have been "strange" (lines 512-515), thereby inviting laughter from Tim (Jefferson, 1979).

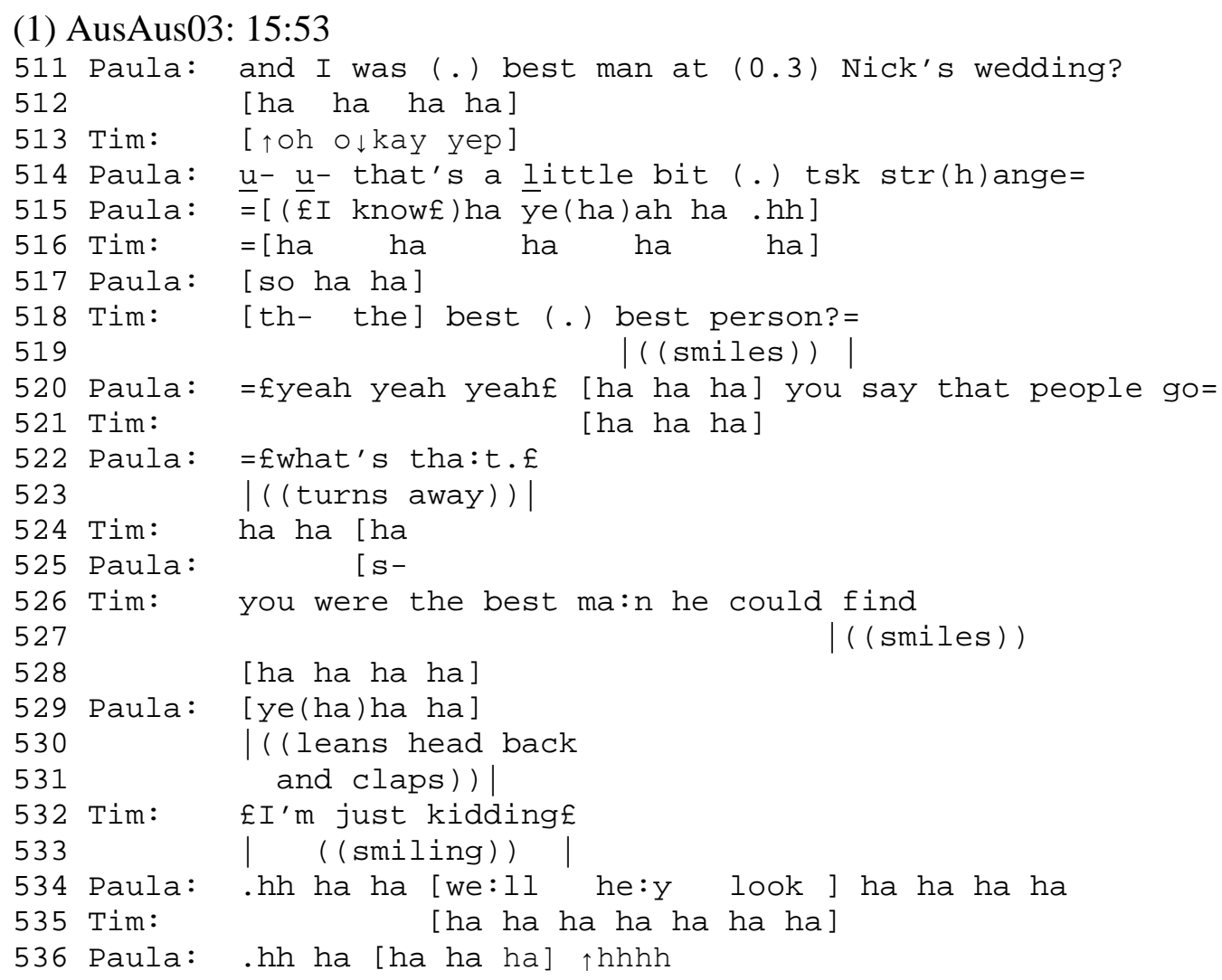

\footnotetext{
${ }^{4}$ Three putative cases of jocular mockery resulted in no audible laughter from recipients, however, and so could be classed as instances of "failed" humour (Bell, 2015).
} 
The mockery in question starts in line 518, but is further upgraded in line 526 when Tim alludes to the absurdity of having no male friends to act as best man at a wedding. However, through the visible smile and turn-final laughter delivered by Tim subsequent to the tease (lines 527-528) (Ford and Fox, 2010; Glenn, 2003; Jefferson, 1979; Schenkin, 1972), and the expression of accord, laughter and clapping appreciation in response from Paula (lines 529531) (Drew, 1987; Ford and Fox, 2010; Glenn, 2003; Jefferson, Sacks and Schegloff, 1987), the mockery is evidently interactionally achieved as jocular. Notably, the target of this jocular mockery is ambiguous as to whether it is directed at a third party, Nick, for being a groom who apparently has no (suitable) male friends, or the co-present other-party, Paula, for being a female who has been asked to take up a male role, although both are inferable as targets of the jocular mockery. Yet no matter how the target(s) of the jocular mockery are interpreted by these participants, the subsequent claim by Tim to be "just kidding" (line 532), does not appear to be necessary for Paula to recognise or appreciate the humour here, given the design of the tease itself (lines 526-527), and their subsequent shared laughter (lines 528-531). Instead, the expression seems to primarily function here as a bid to return to a serious frame (Skalicky, Berger and Bell, 2015). This bid to move back to a serious frame is something which Paula appears to be orienting to through the incipient account in line 534 that is framed as non-straightforward through 'well'-prefacing (Heritage, 2015), but it is subsequently abandoned as they return to engaging in shared laughter (lines 534-537).

In the next example, Jeff and Jill, a romantically involved couple, are talking long distance on the phone, as Jill is away visiting a friend. ${ }^{5}$

\section{(2) SBCSAE028: 6:17}

377 Jeff: ohh: >So you guys have been having a good time<.

378 Jill: un $\downarrow$ hu::nh, $\int \downarrow$ s:uch a good time. It's $\uparrow$ so good to

379 $\downarrow$ see her $\int$.

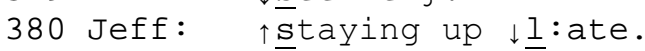

381 Jill: Eunhunhe? [ we $]$ se stayed up till like $($.$) three=$
382 Jeff:

$383 \mathrm{Jill}$ :

384 =thirty last night.

Jeff:

388 Jeff

388 Jeff:

390

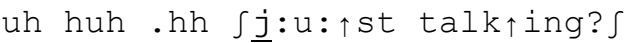

eh heh heh heh huh

391 Jeff:

392 Jill:

393 Jeff:

394 Jill:

395 Jeff:

396 Jill:

$$
\begin{aligned}
& \text { (๑.4) }
\end{aligned}
$$

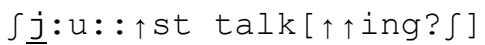

=ha ha ha=

[uh huh ] huh huh=

$=$. hhh: $\int \uparrow$ we have a lot to catch $\uparrow$ up $\downarrow$ o: : :n $\int$.

$£ I: \downarrow k n o: w £$. \#I know. I'm just kidding\#.

tsk $\int$ what have $\uparrow$ you been up to: $\int$.

The excerpt begins with Jill admitting to having stayed up very late while staying with her friend (lines 381, 383). This is in response to Jeff's suggestions, delivered in the form of the candidate answers immanent to his questions in lines 377 and 380 (Pomerantz, 1988), that having a good time involves staying up late. Jeff then seeks an account for these late nights in offering that they've likely been "talking” (lines 385-386). Jill responds that they've been

\footnotetext{
${ }^{5}$ A notable feature of this whole conversation is the frequent use of a "treacle-like" or "sweet" voice quality by both participants, which is here represented by ' $\int$ '.
} 
"just talking” delivered with a "treacle-like” voice quality (line 387), with the "just" emphasising they haven't been doing anything else besides talking (Lee, 1987; Wierzbicka, 2003: 350), and so displays the inference that Jeff may have been suspecting they have been up to other things. Jeff then mocks Jill's account by repeating it twice in lines 388 and 391, thereby implying that Jill must have engaged in other questionable activities besides talking to have been staying up so late. This mockery is jointly accomplished as non-serious through the exaggerated vowel lengthening in Jeff's repetition of Jill's account that marks it as a laughable (Ford and Fox, 2010; Straehle, 1993), along with laughter in response from Jill in lines 389 and 392, with which Jeff joins in as well in line 393 (Drew, 1987; Glenn, 2003; Jefferson, Sacks and Schegloff, 1987). Jill then proffers a serious rejection of the tease, or what Drew (1987) terms a "po-faced” response.

Notably, then, the subsequent claim by Jeff to be "just kidding” (line 395), does not appear to be necessary for Jill to recognise or appreciate the humour here given her laughing responses in lines 389 and 392. Instead, the use of the expression appears to constitute a bid to close the teasing sequence and return to serious talk (Skalicky, Berger and Bell, 2015), a bid which this time is successful, as Jill goes on to ask what Jeff has been doing while she's been away (line 396). However, given it follows a po-faced rejection of tease in question it appears to constitute a possible instance of third position repair (Schegloff, 1992; Schegloff, Jefferson and Sacks, 1977). Specifically, in prefacing the claim to non-serious intent with a repeated "I know", Jeff disputes Jill's claim to epistemic authority and accomplishes an epistemic stance that is incongruent with her just prior epistemic stance (Heritage and Raymond, 2005). In this way, he implicitly treats her po-faced rejection of his tease as inapposite.

While claims to non-serious intent can be made by speakers to acknowledge instances of failed humour or anticipate possible offence (Bell, 2015; Skalicky, Berger and Bell, 2015), in these cases, as we have seen, the mockery is interactionally achieved as jocular. The deployment of such expressions thus appears to be doing other kinds of interactional work, a point which we will return to discuss in further detail in section four. However, before doing so, we will first move to consider another type of teasing sequence in which claims to nonserious intent appear to be constitutive of the tease itself.

\subsection{Jocular pretence}

The second form of teasing to emerge from the analysis encompasses what is here termed “jocular pretence". Pretence involves the expression of what the speaker believes to be false, and comes in either overt or covert forms (Dynel, 2014, forthcoming). Jocular pretence is a form of teasing that involves speakers figuratively setting up addressed recipients through first delivering an assessment, claim or question as ostensibly serious (i.e. without any cues to a jocular stance on the part of the speaker), and then subsequently revealing themselves to be non-serious through claiming non-serious intent and concurrent laughter. While it has affinities with what Sherzer (2002) calls "put-ons" where "an addressee in a conversational interchange or an audience is tricked into believing that something is the case that is actually not the case” (p.53), the deception is only momentary (Dynel, forthcoming), as the speaker subsequently retracts that assessment, claim or question through a claim to non-serious intent. ${ }^{6}$ These claims were found to be delivered either in the transition space following the ostensibly serious question or claim, before the recipient has responded, or in third turn or

\footnotetext{
${ }^{6}$ See also work on related practices, including that by Haddington (2011) who describes "designed sequential ambiguity" resolved through third position repair as particular type of "joke-joke" (vitsi vitsi) practice that is typical of children's talk (p.158), and the "joke first" practice noted by Schegloff (1987), where "before providing the serious 'next', which is sequentially relevant, the participant provides a joke first” (p.212).
} 
position, after the recipient has responded (Kitzinger, 2013), although in both cases the producer orients to possible serious inferences that the recipient may have made in response to what turns out to be a non-serious tease. What is initially designed as a form of covert pretence is thus revealed to be an overt form of pretence, and so jocular pretence constitutes a playfully deceptive form of teasing (Dynel, forthcoming; Hopper and Bell, 1994: 297). ${ }^{7}$ Notably, laughter on the part of the recipients in such teasing sequences, if it did occur, was always delayed and not contiguous with the tease itself, but rather was found to be contiguous with the subsequent claim to non-serious intent.

In the following excerpt from a conversation between an American (Kay) and an Australian (Gillian) who are getting acquainted, for instance, the tease arises in a selfpresentation sequence (Svennevig, 1999; Maynard and Zimmermann, 1984), which is initiated when Kay asks what Gillian is studying in her undergraduate degree.

(3) AmAus22: 10:45

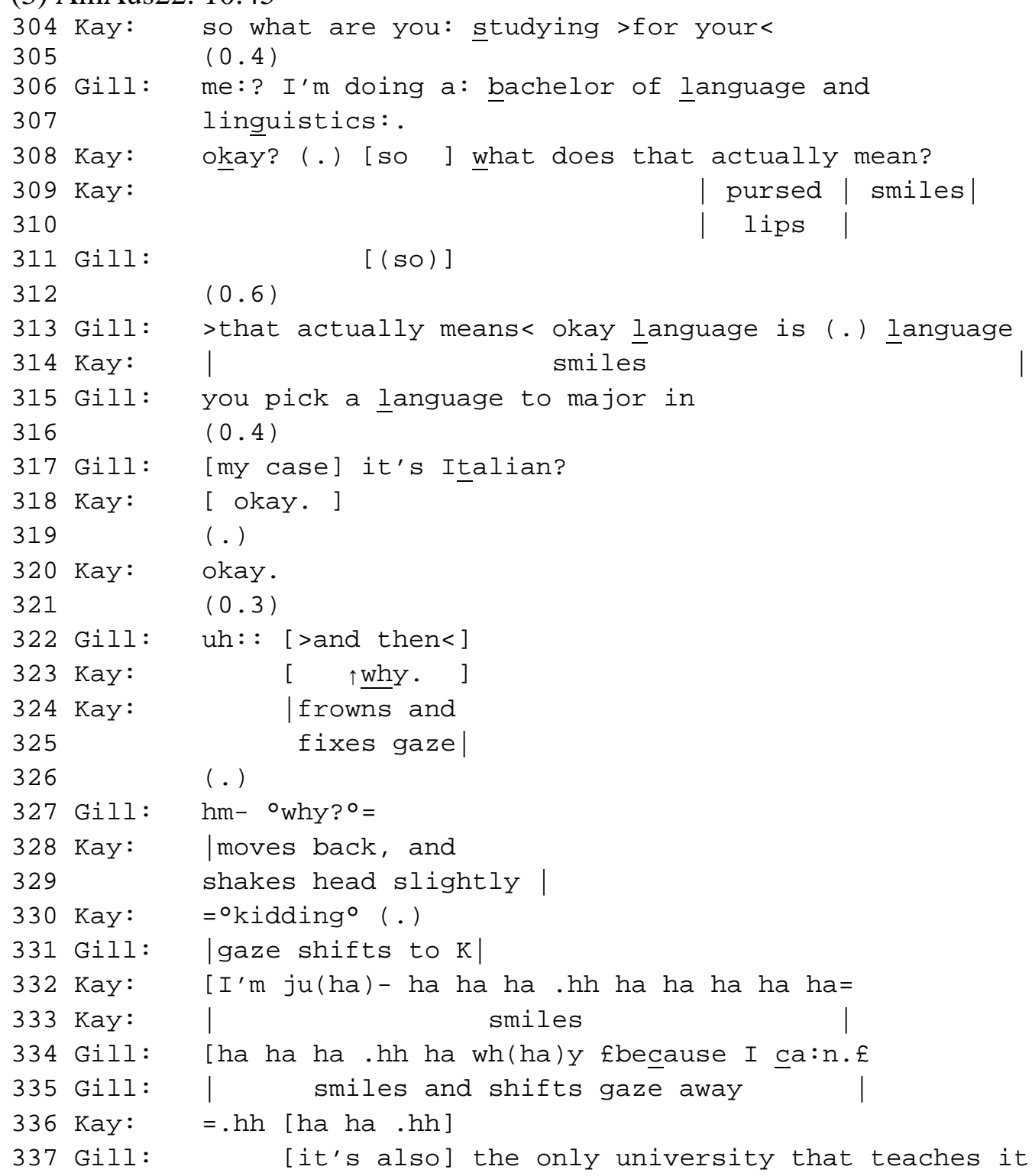

\footnotetext{
${ }^{7}$ Jocular pretence contrasts with instances of deceptive jocular pretence (Dynel, forthcoming), that is, where the producer is in fact only pretending to joke (Vincent and Castelfranchi, 1981), for his or her own amusement or that of an over-hearing audience. As one of the reviewers pointed out, however, in some cases at least, overt instances of jocular pretence may be masking covert instances of deceptive jocular pretence.
} 
The sequence in question begins with Kay's inquiry about what is involved in a Bachelor of Language and Linguistics (line 308). Gillian explains that "language is language" and that she's doing Italian. Notably, Kay indicates “a 'state of readiness' for moving to nextpositioned matters” (Beach, 1994: 339) through repeating “okay” (lines 318, 320) rather than treating this is as new information (e.g. through the change of state token 'oh', Heritage [1984b]). As Gillian moves into further explanation, Kay overlaps with a "why” (line 323), which not only solicits an account for Gillian's choice of language, but implicates criticism for this choice by "index[ing] a measure of epistemic access to the accountable event and communicat[ing] a stance that it does not accord with common sense and thus is possibly inappropriate or unwarranted” (Bolden and Robinson, 2011: 115). This account solicitation and implicated criticism, is delivered as a seemingly serious challenge through both its prosodic contour and Kay's shift from smiling (line 314) to frowning and concurrent fixing of her gaze with Gillian (lines 324-325) as she utters it. Gillian then launches other-initiated repair in line 327 through a full repeat that treats Kay's questioning action itself as problematic (Robinson and Kevoe-Feldman, 2010), while Kay herself maintains a serious stance through shaking her head (lines 328-329). Kay subsequently delivers a claim to nonserious intent in sotto voce (line 330), with Gillian returning her gaze to Kay in response, followed by a repeat of the claim to non-serious intent by Kay that dissolves into laughter and concurrent smiling (lines 332-333). Gillian responds with shared laughter and smiling (lines 334-335), before subsequently offering a serious account for why she is doing Italian (line 337). In this way, Kay's prior ostensibly serious challenge is revealed to be a playful pretence on her part that is subsequently interactionally achieved as a jocular tease, specifically, a form of jocular pretence. ${ }^{8}$

An instance of jocular pretence can also be observed in the following excerpt from a phone call between a daughter (Rhonda) and her mother (Madison), in which Rhonda brings up a previous arrangement to confirm that Madison (and others) will be coming to visit.

(4) CallFriend Engs6914: 4:22

167 Rhon: we:ll, are $y^{\prime}$ a:ll comin?

$168 \quad(0.2)$

169 Madi: yea:h?

$170 \quad(0.4)$

171 Rhon: really?

172 (0.2)

173 Madi: ${ }^{\circ}$ yea:h? ${ }^{\circ}$

$174 \quad(0.6)$

175 Rhon: $\downarrow$ r:eally. (.) no I'm just kiddin' ha $\uparrow \mathrm{HA}$.hh

176 Madi: $\uparrow \mathrm{oh}(\mathrm{hh})$

177 Rhon: goo:d, I'm gla:d, I'm- I can't wait,

178 because (.) I- I: saw on the TV:? hh

179 Madi: $\mathrm{h}[\mathrm{h}]$

180 Rhon: [th]a:t Hancocks is havin- a big sa:le.

181 Madi: .hh I sa: $\bar{W}$ that $\uparrow$ too.

Madison subsequently orients to the agenda underpinning Rhonda's confirmation question with stretched and rising intonation on "yeah" (line 169). However, rather than moving to reveal this possible agenda, Rhonda issues a mildly doubt-implicative "really" (line 171), which is followed by Madison once again orienting to an underlying agenda through

\footnotetext{
${ }^{8}$ Whether this is also interpretable as a covert form of deceptive jocular pretence remains a possibility, as pointed out by one of the reviewers, although there is some evidence prior to the delivery of " $\uparrow$ why" in line 323 that a non-serious frame is already in preparation by Kay (e.g. lines 308-310).
} 
stretched and rising intonation on "yeah" (line 173). Madison then delivers another confirmation seeking "really" (line 175), but this time with a marked downward intonation that implicates a negatively-valenced affective stance towards this proposed visit, possibly disappointment (Couper-Kuhlen, 2012), thereby revealing her ostensible agenda in repeatedly seeking confirmation from her mother about the visit. This is followed, in the transition space subsequent to Rhonda's turn with a 'no'-prefaced claim to non-serious intent (line 175), which orients to the negative inferences that may have been made by her mother (Raclaw, 2013), and turn-final laughter, which invites laughter (Jefferson, 1979). ${ }^{9}$ The mother responds in line 176 with a laughter-implicative change of state token that indicates this nonserious intent constitutes "new information” for her (Heritage, 1984b). The doubt and possible disappointment is thus interactionally achieved as a form of non-serious teasing on Rhonda's part, specifically jocular pretence. The daughter then confirms she is glad they are coming to visit (lines 177-180), thereby also revealing her actual agenda behind wanting to confirm their arrangements for the visit (namely, her excitement about going to the sale with her mother).

Jocular pretence is thus a form of teasing accomplished through the tease being delivered without any cues to non-seriousness, and laughter on the part of the recipient being delayed (i.e. it is not contiguous with the tease itself) until after delivery of the claim to non-serious intent on the part of the producer. Jocular pretence thus differs from jocular mockery in two key ways. First, the tease is delivered (faux) seriously without any cues to jocularity, while in the case of jocular mockery the tease is often, albeit not always, delivered with cues to nonseriousness immanent to its design. Second, laughter in response to the tease is delayed in the case of jocular pretence, while it is contiguous with the tease in the case of jocular mockery. The claim to non-serious intent, then, is thus evidently constitutive of the tease itself in the case of jocular pretence.

In this section, two teasing practices, other-directed jocular mockery and jocular pretence, have been identified in everyday interactions amongst American and Australian speakers of English. We also have seen that in disavowing a prior stance as simply "joking" or "kidding" there is very often much more involved than simply a repair of an alleged "misunderstanding" or lack of appreciation of the humour on the part of addressed recipient, as Skalicky, Berger and Bell (2015) have already noted. By orienting to issues of (non)seriousness and accountability through the use of such expressions, those participants are not only interactionally achieving different forms of jocular teases, but as we shall see in the following section, participants can also accomplish a whole range of different kinds of interactional work through them. In the following section, we thus move to consider the role of claims to non-serious intent with respect to those two practices in more detail.

\section{Claiming non-serious intent as situated social action}

It has already been noted by various humour scholars that claims to non-serious intent can allow producers to retract a "serious" interpretation of their intentions by recipients, as well as to allow "serious" meanings to nevertheless remain implicated (Dynel, 2011). In this way, social actions can be accomplished in ways that are relationally sensitive, as well as affording the speaker a plausible "out” from being held accountable for what could be construed as

\footnotetext{
${ }^{9}$ The sequential structure of jocular pretence accomplished through disclaimers in the transition space arguably bears resemblance to the "not jokes" made infamous in Wayne's World (1992) and subsequently Borat (2006), where speaker assert something as if they are committed to it and then subsequently utter "not" in order make it explicit that they are being sarcastic, as well as implying the recipient (or third party) is gullible and easily misled (see Culpeper and Haugh [2014: 95-96] for a brief discussion of the structure of "not jokes").
} 
offensive by the recipient. ${ }^{10}$ Yet while it has been noted that claims to non-serious intent have various social or interpersonal functions (Haddington, 2011; Kane, Suls and Tedeschi, 1977; Norrick, 1993; Skalicky, Berger and Bell, 2015), what has not been explored in much detail to date is the way in which they constitute inherently moral claims. In this section, it is proposed that this moral dimension is what mediates between the sequential implications (e.g. making a bid to return to serious) and interpersonal implications (e.g. inoculating against negative reactions; accomplishing mutual affiliation and agreement) of these claims to nonserious intent. Claims to non-serious intent with respect to episodes of jocular teasing are thus not only sequentially and interpersonally implicative, but also fundamentally morally implicative as well. It is in this sense, then, that claiming non-serious intent within episodes of teasing constitutes a situated social action in and of itself.

\subsection{Sequential implicativeness}

Sequential implicativeness refers to the way in which a current action makes contingently relevant particular (sets of) actions as properly or appropriately due next actions (Schegloff and Sacks, 1973). In early work on delivering assertions as serious or as jokes, Sacks (1972) noted that joking makes laughter a relevant next, while a serious assertion makes a more complex range of responses relevant as next actions. These initial findings were further developed by Schegloff $(1984,1987)$ who suggested that in some cases there is systematic ambiguity with respect to the (non-)seriousness of a prior action, which can, in some instances, occasion repair. Sequential implicativeness thus refers both to what next actions are contingently relevant, and their expected valence.

As we have already discussed in the previous section, claims to non-serious intent in the case of jocular mockery recurrently indicate a bid on the part of the producer to exit the teasing sequence and return to serious talk. We have already observed an instance of this in example (2) in lines 394-396. In the following excerpts, the same pattern is repeated: subsequent to the producer of the just prior jocular mockery claiming to be "just kidding", the target of the tease produces a serious next turn.

(5) ART: COMne4: 46:03

96 Harvey: $\uparrow$ no d'you wanna ask something else $\downarrow$ I was only

$97 \quad$ [kidding ${ }^{\circ}$ yeah $^{\circ}$.

98 Judy: [üh uh yeah ] I just planted some <avenvue> (.)

99 lavender last october.=

(6) ICE-AUS: S1A-001: 12:20

322 George: £ye:ah mate I kno:w£

323 George: ${ }^{\circ} £ I^{\prime} m$ only jo:kin. $£^{\circ}$

$324(12.0)$ ((other participants in the group are talking in

325

the background))

326 Mark: > I tell you what< Ma:nly went up a <few knots>

327 didn't they la:st $\uparrow$ wee $: k$

\footnotetext{
${ }^{10}$ Such work is often glossed by humour researchers as the mitigation of (potentially) face threatening acts, a set of terminology I purposefully avoid here in order to afford a more complex, multi-layered analysis of claims to non-serious intent as a form of situated social action. While such glosses might seems plausible, it is debatable just how much they really tell us about how these expressions recurrently accomplish various social or interpersonal functions, especially if such claims are not explicitly tied in some way to the talk and conduct of participants themselves.
} 
(7) CallFriend Engn6239: 4:47

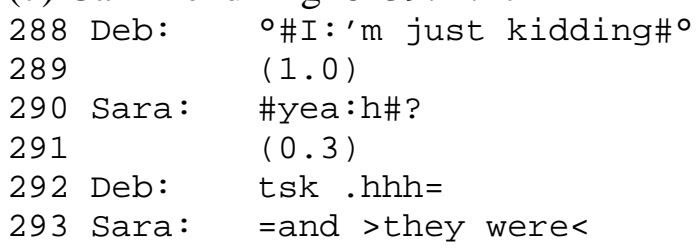

A bid to return to serious may be unsuccessful though, as we previously saw in example (1) in lines 532-535, where the bid was abandoned in favour of further shared laughter.

In the case of jocular pretence, however, claims to non-serious intent are constitutive of the tease itself, and thus make laughter from the recipient a contingently relevant next response. Any return to serious talk thus properly follows laughter. We have already observed an instance of this in example (3) in lines 330-335. In the following excerpts, the same pattern is repeated: subsequent to the producer of the just prior jocular pretence claiming to be "just kidding", the target of the tease produces laughter (examples 8-9) or incipient laughter through interpolated aspiration particles (Potter and Hepburn, 2010) in the talk (example 10).

(8) AmAm05: 0:49

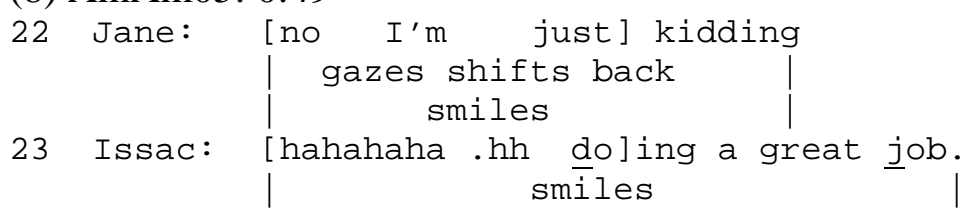

(9) CallFriend Engn6015: 3:35

111 Cath: $\quad \downarrow>I^{\prime} m$ just kid(ding)<=

112 Jess: $=0(\mathrm{hh}) \mathrm{h}$ huh huh huh .hhhhh and

(10) CallFriend Engs6914: 4:26

175 Rhon: no I'm just kiddin' ha $\uparrow$ HA .hh

176 Madi: $\uparrow$ oh $(\mathrm{hh})$

Notably, while in a number of cases these claims to non-serious intent are 'no'-prefaced, thereby indicating a bid to return to serious talk (Schegloff, 2001), as well as an orientation to potentially problematic inferences on the part of the recipient (Raclaw, 2013), in the case of jocular pretence, where the claim to non-serious intent constitutes the tease itself, what immediately follows such a claim is recurrently not serious talk but rather laughter.

Pursuing a laugh response through constituting a prior serious claim as jocular pretence may, of course, be unsuccessful in some instances, as we can see in example (11) below, which constitutes a candidate instance "failed humour" (Bell, 2015)

(11) CallFriend Engn6869: 5:59

400 Matt: I'm just kidding about the\# .hh=

401 Gus: $=\mathrm{h}[\mathrm{h}$ : $]$

402 Matt: [\#neighbor]hood\# (.)

403 Matt: . hhh=

404 Gus: =yeah

It is also worth noting that a subsequent claim to non-serious intent may also indicate a bid to return to serious talk following the interactional accomplishment of an ostensibly serious proposal as an instance of jocular pretence, as we can observe in the example below 
(cf. example 9). The excerpt is from a telephone call between two friends, Emily and Francis. Francis is talking about her latest assignment, writing a children's story.

(12) CallFriend Engn6015: 3:26

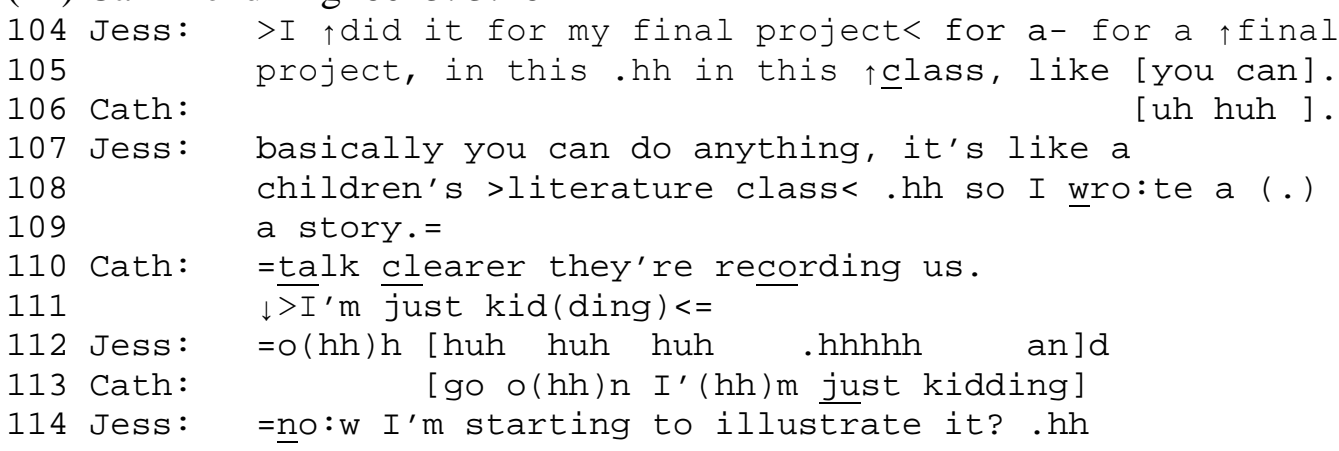

It is her claim that "basically you can do anything" in line 107 that appears to occasion Emily's ironic warning that Francis may land herself in trouble given the call is being recorded (line 110). Emily follows this with a claim to non-serious intent, thereby constituting the prior warning as an instance of jocular pretence (line 111), which occasions, in turn, recognition of this as new information (Heritage, 1984b) and laughter from Franics (line 112). Emily then delivers a second claim to non-serious intent in line 113, which although interpolated with laughter, nevertheless, constitutes a bid to return to serious talk. This is evident from the subsequent return to news telling by Francis (line 114).

In sum, then, claims to non-serious intent are sequentially implicative in two recurrent ways. They may indicate a bid to return to serious talk, as already noted by Skalicky, Berger and Bell (2015), but they may also indicate pursuit of a laugh response in the case of instances of jocular pretence. While claims to non-serious intent were found to co-occur with both of these teasing practices, claims to non-serious intent in the case of jocular pretence are constitutive of the tease itself, in contrast to jocular mockery where the tease itself is delivered and/or responded to as non-serious. Although in both cases the claim may represent a bid to return to serious talk, in the case of jocular pretence any such return to serious talk is positioned as properly due only after the recipient displays recognition and/or appreciation of the tease through laughter, while in the case of jocular mockery a return to serious talk is positioned as properly due in next position.

\subsection{Moral implicativeness}

Claiming non-serious intent is also morally implicative in that it can impact on the degree to which participants may be legitimately held accountable for the potentially serious implications of the tease in question, and the degree to which recipients are licensed to take offence. However, as we shall see in this section, claiming non-serious intent does not simply pre-empt offence, but represents a deeply moral claim through which participants also acknowledge possible offence, sanction the recipient for taking themselves (or things) too seriously, or dispute the appositeness of the claim to non-serious intent itself. It is for this reason that claims to non-serious intent have a number of inter-related interpersonal implications, such as indexing or inviting intimacy, establishing relational hierarchies or "pecking orders" in groups, or attributing particular identities to participants (Haugh, 2014, forthcoming a). 
It has already been previously noted that a claim to non-serious intent may "inoculate" the speaker by pre-empting any taking of offence by recipient(s) before the recipient has responded to the tease (Bell, 2015; Skalicky, Berger and Bell, 2015). However, producers may also block the taking of offence that might otherwise be licensed by the tease by following a serious response from the recipient with a subsequent claim to non-serious intent. Whether pre-empting or blocking the taking of offence, a claim to be "just kidding" and the like is not so much an appeal to the privately-held intentions of the speaker as much as an attempt to undermine the moral grounds for the recipient to take offence. The expression, "just kidding", licenses the inference that one who displays negative feelings in response to jocular teasing is open to the charge of taking themselves too seriously (Goddard, 2009; Haugh and Bousfield, 2012; Haugh, forthcoming a). In this way, then, through claiming nonserious intent, the producer implements the implicit claim that the recipient does not have an affective entitlement to take offence at the tease.

In the following example from a conversation between Jeff and Jill, a romantically involved couple, they have returned to talking about Jill's news delivered at the beginning of the call that she thought she might have been pregnant. Immediately prior to this excerpt, Jill has been talking about her emotional reaction to the pregnancy scare, namely, that she felt "scared". The excerpt begins with a potential shift in footing from Jill as the troubles teller to Jeff alluding his own possible troubles if she had indeed turned out to be pregnant.

(13) SBC028: 21:41

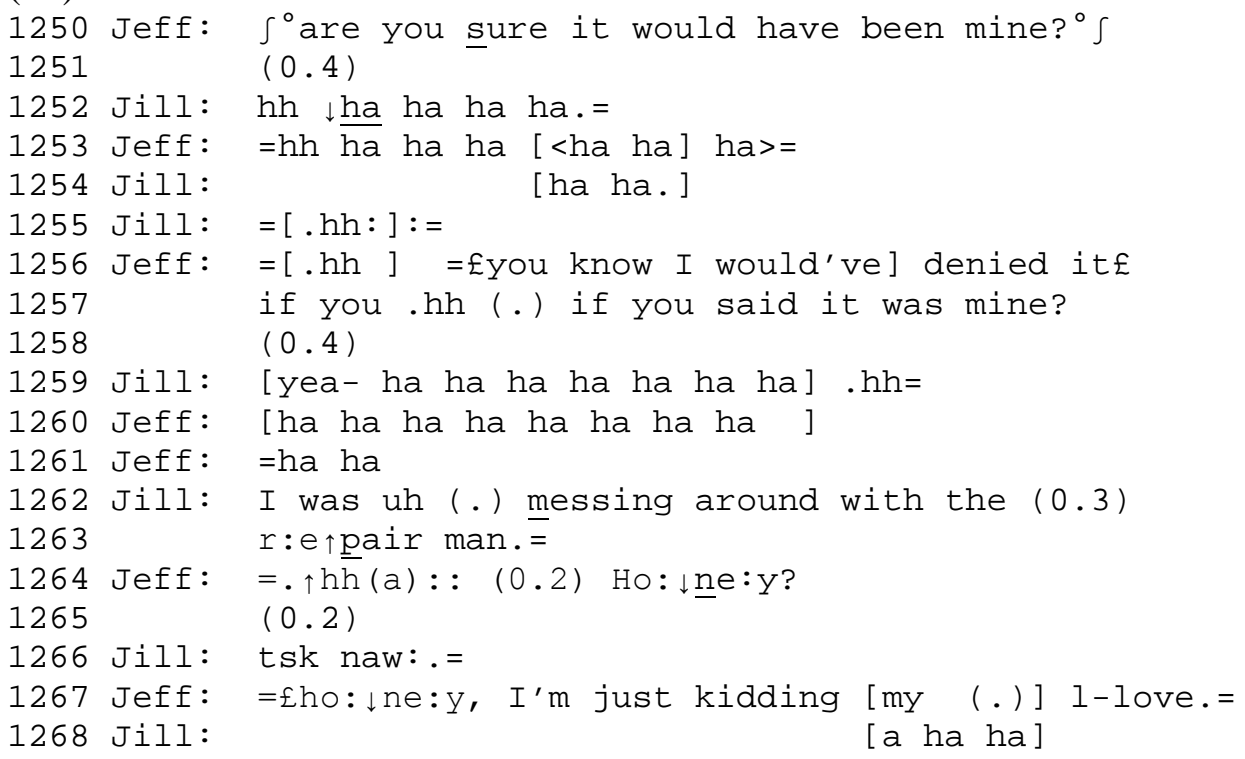

The sequence begins with Jeff raising the issue of whether Jill could have been sure about who the father was if she had turned out to be pregnant (line 1250). While there are no cues to a jocular or playful stance in the design of this question, Jill construes it as simultaneously non-serious as well as a potentially bit "close to the bone" (Hopper, 1995) through laughter that is hearably “forced” (Haakana, 2012). Jeff's subsequent laughter in line 1253 recontextualises the ostensibly serious question as jocular, constituting an invitation to shared laughter (Jefferson, 1979). The subsequent tease in lines 1256-1257 is cued as jocular through "smile voice", which invites treatment of his claim as a laughable (Jefferson, 2004b; Holt, 2010). This leads to shared laughter (lines 1259-1261), followed by subsequent elaboration of the jocular mockery by Jill (lines 1262-1263).

In light of the fact that Jill has gone along with the non-serious tenor of the teasing sequence, Jeff's subsequent claim to be “just kidding” in line 1267 evidently does not 
constitute an attempt to repair failed humour (Bell, 2015; Hay, 2001). Instead, given the delicate nature of the implicated premise here, namely, that if his girlfriend were pregnant he may not have been the father, Jeff's claim to non-serious intent appears to be working to block any potential for taking (or at least displaying) offence on the part of his girlfriend. An underlying moral dimension of a bid to return to serious talk, which this claim to non-serious intent appears to instantiate, is that it does not license any further response to the tease itself by Jill. It also implicates, in addition, that any serious response to the teasing would be inapposite at this point in the sequence. In this way, then, Jeff implicitly claims that Jill does not have any affective entitlement to take offence at the tease. ${ }^{11}$ The bid to maintain relational connection with Jill that the disclaimer accomplishes is thus refracted through the moral implications of making such a claim.

Another way in which claiming non-serious intent in relation to a previous tease is morally implicative is that it may also constitute a means by which a producer may implicitly acknowledge possible offence on the part of the target. In the following excerpt, for instance, Judy is a caller to a radio talkback show broadcast in Australia where two expert gardeners, Sue and Christine, have been invited to provide advice to members of the public. The conversation with Judy, however, has gone for significantly longer than other call-ins.

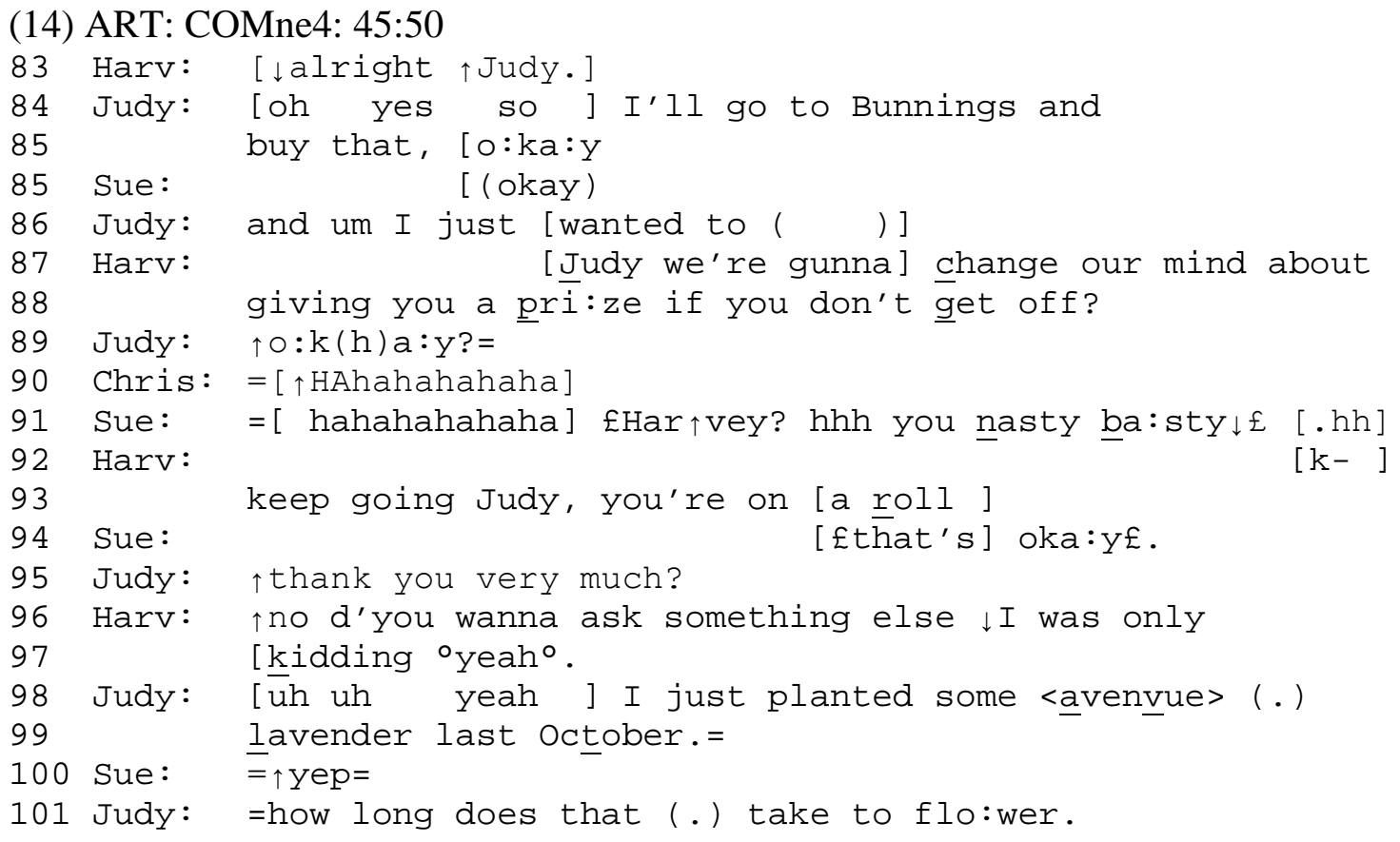

The excerpt here begins with host of the show, Harvey, trying to signal the interaction should end soon through a pre-closing "alright" in line 83 (Schegloff, 1968). However, this is not oriented to by Judy, who first responds in lines 84-85 to just prior advice from Sue (data not shown), but then goes on to initiate another question-answer sequence (line 86). At this point, Harvey interrupts Judy's utterance at a point that is not hearable as a legitimate transition relevance place (Sacks, Schegloff and Jefferson, 1974) with a threat to withdraw the call-in prize she has previously been awarded (lines 87-88). While Judy responds in line 89 with a breathy, high-pitched acknowledgement of assent (i.e. to end the call), which she precedes to initiate through a pre-closing thanking in line 95 (Schegloff and Sacks, 1973), the non-serious

\footnotetext{
${ }^{11}$ Jill may, of course, have felt offended at some level although this does not surface in the conversation in question. In making the analytical claim that Jeff is blocking any taking of offence at the jocular teasing, taking offence itself is being treated as a social action (Haugh, 2015b) distinct from any privately-held feelings of offence.
} 
framing of this threat is oriented to by the other participants in the intervening turns. There is first joint laughter from the two expert presenters (lines 90-91), followed by Sue directing jocular abuse at Harvey (Hay, 2002; Haugh and Bousfield, 2012). She insults him by calling him a "nasty basty", although this is framed as non-serious through the use of "basty" as a diminutive form of "bastard" and its delivery with a "smile voice" that marks the insult as a laughable (Jefferson, 2004b; Holt, 2010). Harvey subsequently exhorts Judy to "keep going” as "she is on a roll" (line 93), while Sue indicates it is okay for Judy to continue with a hearable "smile voice" (line 94). The equivocality of whether this invitation to continue is indeed serious is reflected in Judy's subsequent move to close the sequence through a preclosing thanking, and Harvey’s “no"-prefaced offer for her to ask another question (line 96), which thereby signals a move back to a serious stance (Schegloff, 2001), and his subsequent claim to have been "only kidding” (lines 96-97).

While the expression indicates a bid to return to serious talk, the question remains as to why it has been invoked when the prior tease was interactionally achieved as jocular by the participants? Its occurrence may be due, in part, to the uptake of Judy herself who appears to orient to the jocular threat as a serious request on Harvey's part that she finish her call. It thus appears that Harvey is proffering acknowledgement of the possibility of having "gone too far" or "too close to the bone" with his mocking threat (Hopper, 1995), and thereby construes the jocular mockery itself as a potential impropriety. In this way, he is orienting to possible feelings of offence on Judy's part, while at the same time disclaiming responsibility for any such feelings. ${ }^{12}$ However, given this is implicated through the use of the expression, this acknowledgement remains "unofficial", and is not explicitly oriented to by Judy in her subsequent turn, when she goes on to ask another question (lines 98-99). Notably, this acknowledgement of a possible impropriety on his part is also identity implicative, in that through it Harvey is able to block any further construal of himself as an "impolite" or "insensitive" person.

A third way in which claims to non-serious intent can be morally implicative is that through such a claim, the producer can implicitly sanction a recipient for taking themselves too seriously (Emerson, 1969: 178). In other words, claims to non-serious intent not only constitute an interpretive but also an evaluative resource for participants. In the following excerpt, for instance, a claim to non-serious intent is invoked subsequent to a serious response to what appears to have been designed as an instance of non-serious, jocular mockery. Just prior to where this excerpt begins, George, who is in his 70s, and Mark, who is in his late 40s, have been talking about a string of losses by a particular rugby league team they both follow in New South Wales, Australia. They have just been commiserating each other about yet another loss by the team they both support.

(15) ICE-AUS: S1A-001: 12:11

314 Mark: well I don't know <what (.) what went wrong> with

315

316 Georg:

317 Mark: =did go wrong?

318 Georg: ${ }^{\circ}$ they mi:ght be ca:mera shy ${ }^{\circ}($.$) oh na: (h) h$

319 Georg: >hheh heh [heh<]

320 Mark: $\quad[\overline{0}:: h]$ shi:t they've had enough

321 [T:V: games this year] to snap out of that sort of=

322 Georg: [fye:ah mate I kno:w£]

323 Georg: $={ }^{\circ} £ I$ 'm only jo:kin. $£^{\circ}$

$324(12.0)$ ((other participants in the group are

${ }^{12}$ Given this interaction is broadcast, Harvey is also pre-empting the vicarious taking of offence by listeners. 
326 Mark: >I tell you what< Ma:nly went up a <few knots>

Mark subsequently bemoans once again that the team played very badly in their last game (lines 314-315, 317). His negative stance is formulated as serious through both its delivery with emphatic stress, as well as the intensifier adverb "bloody". Yet rather than affiliating with this negative assessment through a second assessment (Goodwin and Goodwin, 1987), George instead offers an account in line 318 for the team's poor performance, namely, that since the game was televised it somehow unnerved them. ${ }^{13}$ In this way, he implicitly undermines the grounds for Mark's complaint about the team (Drew, 1998). However, there are various indicators that this account is designed as a non-serious one. Prosodic cues to a non-serious framing of this account include its delivery at a lower pitch and a softer volume, which is typical of "deadpan” delivery (Haugh and Bousfield, 2012). In addition, the subsequent "no" in the transition space immediately following the account (line 318) indicates rejection of that account by George himself, thereby implicating a non-serious stance in relation to the just prior account. The rejection is also followed by turn-final laughter particles (line 319), which here construe the prior account as a laughable and invite Mark to join in with laughter (Jefferson, 1979).

Yet despite these various cues to a non-serious design, Mark's subsequently orients to George's account as serious in emphatically rejecting it (lines 320-321). While Mark is rejecting that account, George himself claims in overlapping speech (line 322) that he did not really think the camera had an effect on the team's performance, and so undermines the epistemic grounds for Mark's assertion, that is, George already knows what Mark is apparently trying to dissuade him of thinking. George then explicitly positions his previous account as "only joking” (line 323). The overlapping epistemic claim in line 322, and the disavowal of a serious stance in line 322, are both delivered with a "smile voice", which not only resists Mark's epistemic claim in treating his own epistemic claim as a laughable (Jefferson, 2004b; Holt, 2010), but also indicates a disaffiliative stance with respect to Mark's serious construal of his account (Greer et al., 2005). The conversation between them then lapses for a significant period (lines 324-325), before Mark restarts his conversation with George through a stepwise topic transition (Jefferson, 1984). The lack of an immediate response from Mark to George's disavowal of taking a serious stance thus constitutes a possible noticeable absence, although what inferences might be licensed by this lack of response remains indeterminate.

George's disavowal is thus not simply an instance of third positon repair. Instead, it also arguably constitutes a mild sanction of Mark. In essence, by claiming "I'm only joking" George licenses the inference that Mark is being overly serious both with respect to his response to the non-serious account itself, and in his complaints about the team in question. This construal of Mark as overly serious indicates a possible negative evaluation of him by George, given the negative evaluations that "taking yourself too seriously" are said to license amongst Australian speakers of English (Goddard, 2009). ${ }^{14}$

\footnotetext{
13 This recording was made in the early 1990s when games in state-based competitions were only just first being televised live in Australia.

${ }^{14}$ It is important to note that negative evaluations of people who "taking themselves too seriously" are not necessarily limited to Australian speakers of English (Culpeper and Haugh, 2014: 256-257; Haugh and Bousfield, 2012). Vincent Marrelli (1994), for instance, claims that amongst southern Italian speakers sanctions may be directed at those who respond seriously to teases. However, while the way in which claims to nonserious intent may constitute a criticism of the recipient is likely to vary cross-culturally, as one reviewer pointed out, a consideration of this lies outside of the scope of the current paper.
} 
Finally, in some instances claims to non-serious intent may be morally implicative in the sense that through them participants may claim or dispute the timing of the recipient's recognition of the producer's non-serious intent. This is potentially a moral matter because timely recognition of the producer's non-serious intent may be construed as apposite or inapposite. In the following excerpt, a couple, Wendy and Kevin have been co-telling a story to some friends, Marci, Ken, and Kendra, with whom they are playing cards, about how they ran into a suspicious character while out shopping.

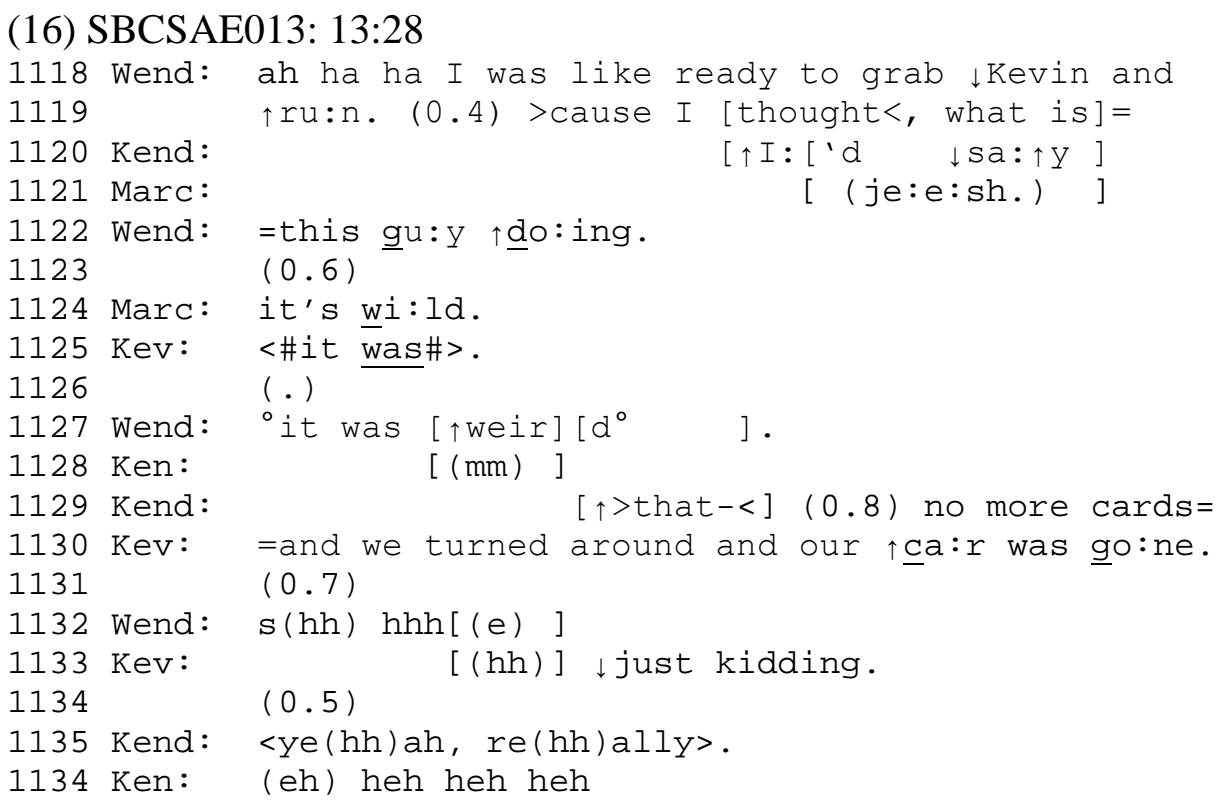

The end of the storytelling sequence appears to be reached when Marci offers an assessment of it as "wild" (line 1124), followed by a co-constructed assessment of the experience as "weird" (lines 1125-1127) through which the story co-tellers affiliate with Marci's stance (Stivers, 2008). However, Kevin goes on to make the subsequent claim that their car was stolen as a post-script to the telling (line 1130). Wendy bursts into laughter (line 1132), while Kevin claims to be "just kidding” (line 1133), thereby construing the prior claim as jocular pretence. However, Kendra's subsequent response treats Kevin's just prior claim to nonserious intent as inapposite, by implicating that it was already obvious his claim was not a serious one (line 1135). This inference is further warranted by the interpolated laughter through which Kendra implies "that there is more going on than the mere use of the word would indicate” (Potter and Hepburn, 2010: 1546). That Kendra is mocking Kevin for assuming they wouldn't "get” the tease without him claiming non-serious intent is also evident from Ken's subsequent laughing response (line 1134). In this case, then, the recipients are holding the producer accountable for an inapposite, specifically, an unnecessary claim to be "kidding."

\section{Conclusion}

In this paper, claims to non-serious intent made in episodes of teasing through expressions such as "just kidding” have been examined. It has been suggested that close analysis of such sequences reveals two distinct practices by which teasing may be accomplished, jocular mockery and jocular pretence. In the latter case, claims to non-serious intent are construed by the producers as constitutive of the tease. These practices are also revealed as distinct through the design of the tease itself (i.e. whether it is delivered as serious or non-serious), whether 
laughter from recipients is contiguous with the tease or delayed, and what next action is made contingently relevant by a claim to non-serious intent (i.e. a return to serious talk or laughter). However, it was subsequently claimed that claims to non-serious intent are not only sequentially implicative, but morally implicative as well. The moral work accomplished through claims to non-serious intent include pre-empting or blocking the taking of offence to the tease, acknowledging a possible impropriety, sanctioning a recipient for taking things too seriously, and disputing the appositeness of the claim to non-serious intent itself. It has been further argued that the interpersonal or social functions of claims to be "just kidding" that have been attested to in previous studies are mediated through these locally situated sequential and moral implications. Analysing interpersonal and evaluative aspects of interaction, such as offence, impropriety, relationships and identities, thus requires that close analytical attention be directed to the interactional achievement of social action and (pragmatic) meaning. It is concluded from this analysis that claiming non-serious intent constitutes a social action in and of itself that is sequentially and morally implicative. Analyses of the interpersonal implications of teasing should thus be undertaken in ways that address the sequentially and morally implicative nature of teasing.

The findings in this study also have implications for our understanding of the role of intention in humour more broadly. The conceptualisation of intent that has been drawn upon in this paper has been a fundamentally discursive one. Intention has been treated as a publicly construable mental process rather than a privately held mental state of individuals. The account of intent vis-à-vis humour developed in this paper does not, therefore, offer a straightforward model of what might be going on inside the minds of participants. Instead, it attempts to tap into the inferences available to participants that are licensed by the social actions that such claims instantiate. The interactional work that can be accomplished by participants through claiming non-serious (or indeed serious) intent is complex. Technical, second order accounts of cognition that appeal to lay understandings of intentions must take this discursive complexity into account in order to avoid an overly reductive account of cognition-for-interaction. There thus still remains much to do in order to properly reconcile discursive and cognitive accounts of interaction. Given the oft ambivalence of producers' intentions with respect of different forms of humour, it is clear that studies of humour have the potential to contribute much to this ongoing endeavour

\section{Acknowledgements}

I would like to thank the two anonymous reviewers and Marta Dynel for their very helpful comments on an earlier version of this paper. I would also like to thank Lara Weinglass for her assistance in transcribing the data. Finally, I wish to acknowledge the support of a Discovery grant from the Australian Research Council (DP120100516) that has enabled the research reported in this paper to be undertaken

\section{References}

Alberts, Jess K. 1992. Teasing and sexual harassment: double-bind communication in the workplace. In Perry, Linda A. Turner, Lynn H. and Sterk, Helen M. (eds.), Constructing and Reconstructing Gender. Albany, New York: State University of NY Press, pp. 185196. 
Arundale, Robert. 2008. Against (Gricean) intentions at the heart of human interaction. Intercultural Pragmatics 5: 231-60.

Arundale, Robert. 2010. Constituting face in conversation: face, facework and interactional achievement. Journal of Pragmatics 42: 2078-2105.

Attardo, Salvatore. 1994. Linguistic Theories of Humour. Berlin: Mouton de Gruyter.

Bateson, Gregory. 1955. A theory of play and fantasy. In Approaches to the Study of Human Personality. Washington, D.C.: American Psychiatric Association, pp. 39-51.

Beach, Wayne. 1994. Relevance and consequentiality. Western Journal of Communication 58: 51-57.

Beach, Wayne A. and Dunning, David G.. 1982. Pre-indexing and conversational organization. Quarterly Journal of Speech 68(2): 170-185.

Bell, Nancy. 2015. We Are Not Amused: Failed Humour in Interaction. Berlin: Mouton de Gruyter.

Bolden, Galina B. and Robinson, Jeffrey D.. 2011. Soliciting accounts with whyinterrogatives in conversation. Journal of Communication 61: 94-119.

Couper-Kuhlen, Elizabeth. 2012. Exploring affiliation in the reception of conversational complaint stories. In Peräkylä, Anssi and Sorjonen, Marja-Leena (eds.), Emotion in Interaction. Oxford: Oxford University Press, pp. 113-146.

Culpeper, Jonathan and Haugh, Michael. 2014. Pragmatics and the English Language. Houndmills, Basingstoke: Palgrave Macmillan.

Decapua, Andrea and Boxer, Diana. 1999. Bragging, boasting and bravado: Male banter in a brokerage house. Women and Language 22(1): 5-12.

de Jongste, Henri. 2013. Negotiating humorous intent. In Dynel, Marta (ed.), Developments in Linguistic Humour Theory. Amsterdam: John Benjamins, pp. 179-210.

DiCioccio, Rachel L. 2010. The interactionist model of teasing communication. In Avtgis, Theodore A. and Rancder, Andrew S. (eds.), Arguments, Aggression and Conflict: New Directions in Theory and Research. New York / London: Routledge, pp. 340-355.

Deppermann, Arnulf. 2012. How does ‘cognition' matter to the analysis of talk-ininteraction? Language Sciences 34: 746-767.

Drew, Paul. 1987. Po-faced receipts of teases. Linguistics 25: 219-53.

Drew, Paul. 1998. Complaints about transgressions and misconduct. Research on Language and Social Interaction 31: 295-325.

Drew, Paul. 2013. Turn design. In Sidnell, Jack and Stivers, Tanya (eds.), The Handbook of Conversation Analysis. Malden, MA: Wiley-Blackwell, pp. 103-130.

Dynel, Marta. 2009. Beyond a joke: types of conversational humour. Language and Linguistics Compass 3: 1284-1299.

Dynel, Marta. 2011. Joker in the pack: Towards determining the status of humorous framing in conversation. In Dynel, Marta (ed.) The Pragmatics of Humour across Discourse Domains. Amsterdam: John Benjamins, pp. 217-41.

Dynel, Marta. 2014. Isn’t it ironic? Defining the scope of humorous irony. Humor 27: 619639.

Dynel, Marta. Forthcoming. Lying and humour. In Meierbauer, Jörg (ed.), Oxford Handbook of Lying. Oxford: Oxford University Press.

Edwards, Derek. 2008. Intentionality and mens rea in police interrogations: the production of actions as crimes. Intercultural Pragmatics 5: 177-199.

Emerson, Joan P. 1969. Negotiating the serious import of humour. Sociometry 32 (2): 169181.

Ford, Cecilia and Fox, Barbara. 2010. Multiple practices for constructing laughables. In Barth-Weingarten, Dagmar, Reber, Elisabeth and Selting, Margaret (eds.), Prosody in Interaction. Amsterdam: John Benjamins, pp. 339-68. 
Gibbs, Raymond W. Jr. 1999. Intentions in the Experience of Meaning. Cambridge: Cambridge University Press.

Gibbs, Raymond W. Jr. 2012. The emergence of intentional meaning: a different twist on pragmatic linguistic action. Lodz Papers in Pragmatics 8: 17-35.

Glenn, Phillip. 2003. Laughter in interaction. Cambridge: Cambridge University Press.

Goddard, Cliff. 2009. Not taking yourself too seriously in Australian English: semantic explications, cultural scripts, corpus evidence. Intercultural Pragmatics 6: 29-53.

Goffman, Erving. 1979. Footing. Semiotica 25: 1-29.

Goodwin, Charles and Goodwin, Marjorie Harness. 1987. Concurrent operations on talk: notes on the interactive organization of assessments. IPrA Papers in Pragmatics 1: 1-54.

Greer, Tim, Usui, Yoshiko, Kato, Toki, Taniguchi, Hitomi and Bussinguer Andrade, Vivian. 2005. Suppressing laughter in the display of (dis)affiliation. Kobe Daigakui Kokusai Komyunikeeshon Sentaa Ronshuu (Kobe University International Communication Centre Bulletin) 2: 27-42.

Haakana, Markku. 2012. Laughter in conversation: the case of 'fake' laughter. In Peräkylä, Anssi and Sorjonen, Marja-Leena (eds.), Emotion in Interaction. Oxford: Oxford University Press, pp. 174-194.

Haddington, Pentti. 2011. Serious or non-serious? Sequential ambiguity and disavowing a prior stance. Functions of Language 18: 149-182.

Hatch, Mary Jo and Erlich, Sanfrod E. 1993. Spontaneous humour as indicator of paradox and ambiguity in orgnanizations. Organization Studies 14: 505-526.

Haugh, Michael. 2008. Intention and diverging interpretings of implicature in the "uncovered meat” sermon. Intercultural Pragmatics 5: 201-229.

Haugh, Michael. 2010. Jocular mockery, (dis)affiliation and face. Journal of Pragmatics 42: 2106-2119.

Haugh, Michael. 2012. On understandings of intention: a response to Wedgwood. Intercultural Pragmatics 9: 161-194.

Haugh, Michael. 2013. Speaker meaning and accountability in interaction. Journal of Pragmatics 48: 41-56.

Haugh, Michael. 2014. Jocular mockery as interactional practice in everyday AngloAustralian conversation. Australian Journal of Linguistics 34 (1): 76-99.

Haugh, Michael. 2015a. Im/Politeness Implicatures. Berlin: Mouton de Gruyter.

Haugh, Michael. 2015b. Impoliteness and taking offence in initial interactions. Journal of Pragmatics 86: 36-42.

Haugh, Michael. forthcoming a. Teasing. In Attardo, Salvatore (ed.), Handbook of Language and Humour. London: Routledge.

Haugh, Michael. forthcoming b. Mocking and (non-)seriousness in initial interactions amongst American and Australian speakers of English. In Carbaugh, Donal (ed.), Handbook of Communication in Cross-Cultural Perspective. London: Routledge.

Haugh, Michael and Bousfield, Derek. 2012. Mock impoliteness, jocular mockery and jocular abuse in Australian and British English. Journal of Pragmatics 44: 1099-1114.

Haugh, Michael and Jaszczolt, Kasia M. 2012. Speaker intentions and intentionality. In Allan, Keith and Jaszczolt, Kasia M. (eds.), The Cambridge Handbook of Pragmatics, Cambridge: Cambridge University Press, pp. 87-112.

Hay, Jennifer. 2001. The pragmatics of humour support. Humor 14: 55-82.

Hay, Jennifer. 2002. Male cheerleaders and wanton women: humour among New Zealand friends. Te Reo (Journal of the Linguistic Society of New Zealand) 45: 3-36.

Heritage, John. 1984a. A change of state token and aspects of its sequential placement. In Atkinson, J. Maxwell and Heritage, John (eds.), Structures of Social Action. Cambridge: Cambridge University Press, pp. 299-345. 
Heritage, John. 1984b. Garfinkel and Ethnomethodology. Cambridge: Polity Press.

Heritage, John. 2015. Well-prefaced turns in English conversation: A conversation analytic perspective. Journal of Pragmatics 88: 88-104.

Heritage, John and Raymond, Geoffrey. 2005. The terms of agreement: indexing epistemic authority and subordination in talk-in-interaction. Social Psychology Quarterly 68: 1538.

Holmes, Janet. 2000. Politeness, power and provocation: how humour functions in the workplace. Discourse Studies 2: 159-185.

Holt, Elizabeth. 2010. The last laugh: shared laughter and topic termination. Journal of Pragmatics 42: 1513-1525.

Holt, Elizabeth. 2013. 'There's many a true word said in jest': seriousness and nonseriousness in interaction. In Glenn, Phillip and Holt, Elizabeth (eds.), Studies of Laughter in Interaction. London: Bloomsbury, pp. 69-89.

Hopper, Robert. 1995. Episode trajectory in conversational play. In Ten Have, Paul and Psathas, George (eds.), Situated Order: Studies in the Social Organisation of Talk and Embodied Activities. Washington, D.C.: International Institute for Ethnomethodology and Conversation Analysis and University Press of America, pp. 57-71.

Hopper, Robert and Bell, Robert A. 1984. Broadening the deception construct. Quarterly Journal of Speech 70: 288-302.

Jefferson, Gail. 1979. A technique for inviting laughter and its subsequent acceptancedeclination. In Psathas, George (ed.), Everyday Language: Studies in Ethnomethodology. New York: Irvington, pp. 79-95.

Jefferson, Gail. 1984. On stepwise transition from talk about a trouble to inappropriately next-positioned matters. In Atkinson, J. Maxwell and Heritage, John. (eds.), Structures of Social Action. Cambridge: Cambridge University Press, pp. 191-222.

Jefferson, Gail. 2004a. Glossary of transcript symbols with an introduction. In Lerner, Gene H. (ed.), Conversation Analysis: Studies from the First Generation. Amsterdam: John Benjamins, pp. 13-23.

Jefferson, Gail. 2004b. A note on laughter in 'male-female' interaction. Discourse Studies 6: 117-133.

Jefferson, Gail, Sacks, Harvey and Schegloff, Emanuel. 1987. Notes on laughter in the pursuit of intimacy. In Button, Graham and Lee, J.R.E. (eds.), Talk and Social Organisation. Clevedon, UK: Multilingual Matters, pp.152-205.

Kane, Thomas, Suls, Jerry and Tedeschi, James. 1977. Humour as a tool of social interaction. In Chapman, Antony J. and Foot, Hugh C. (eds.), It's a Funny Thing, Humour. Oxford: Pergamon Press, pp. 13-16.

Kitzinger, Celia. 2013. Repair. In Sidnell, Jack and Stivers, Tanya (eds.), Handbook of Conversation Analysis. Malden, MA: Wiley-Blackwell, pp. 229-256.

Knobe, Joshua. 2003. Intention action and side effects in ordinary language. Analysis 63: 190-194.

Kowalski, Robin M. 2000. 'I was only kidding!’: victims' and perpetrators’ perceptions of teasing. Personality and Social Psychology Bulletin 26(2): 231-241.

Kruger, Justin, Gordon, Cameron, and Kuban, Jeff. 2006. Intentions in teasing: when "just kidding” just isn’t good enough. Journal of Personality and Social Psychology 90(3): 412-425.

Lee, David. 1987. The semantics of just. Journal of Pragmatics 11:377-398.

Levinson, Stephen. 2006a. Cognition at the heart of human interaction. Discourse Studies 8: 85-93.

Malle, Bertram. 2004. How the Mind Explains Behaviour: Folk Explanations, Meaning, and Social Interaction. Cambridge, Massachusetts: MIT Press. 
Maynard, Douglas and Zimmermann, Don. 1984. Topical talk, ritual and the social organization of relationships. Social Psychology Quarterly 47: 301-316.

Mitchell, Nathaniel. 2015. Goading as a social action: non-impolite evaluations in targeted banter. In Terkourafi, Marina (ed.), Interdisciplinary Perspectives on Im/politeness. Amsterdam: John Benjamins, pp 121-148.

Mullany, Louise. 2004. Gender, politeness and institutional power roles: humour as a tactic to gain compliance in workplace business meetings. Multilingua 23: 13-37.

Norrick, Neal. 1993. Conversational Joking: Humour in Everyday Talk. Bloomington, IN: Indiana University Press.

Partington, Alan. 2006. The Linguistics of Laughter. London: Routledge.

Pawluk, Cheryl. 1989. Social construction of teasing. Journal for the Theory of Social Behavior 19: 145-167.

Pomerantz, Anita. 1988. Offering a candidate answer: an information seeking strategy. Communication Monographs 55: 360-373.

Potter, Jonathan and Hepburn, Alexa. 2010. Putting aspiration into words: 'laugh particles', managing descriptive trouble and modulating action. Journal of Pragmatics 42: 15431555.

Raclaw, Joshua. 2013. Indexing inferables and organizational shifts: 'No'-prefaces in English conversation. Unpublished $\mathrm{PhD}$ dissertation, University of Colorado.

Robinson, Jeffrey and Kevoe-Feldman, Heidi. 2010. Using full repeats to initiate repair on others' questions. Research on Language and Social Interaction 43:232-259.

Sacks, Harvey. 1972. An initial investigation of the usability of conversational data for doing sociology. In Sudnow, David. (ed.), Studies in Social Interaction. New York: The Free Press, pp. 31-74.

Sacks, Harvey, Schegloff, Emanuel and Jefferson, Gail. 1974. A simplest systematics for the organisation of turn-taking for conversation. Language 50: 696-735.

Schegloff, Emanuel. 1968. Sequencing in conversational openings. American Anthropologist 70: 1075-1095.

Schegloff, Emanuel. 1984. On some questions and ambiguities in conversation. In Atkinson, J. Maxwell and Heritage, John (eds.), Structures of Social Action. Cambridge: Cambridge University Press, pp. 28-52.

Schegloff, Emanuel. 1987. Some sources of misunderstanding in talk-in-interaction. Linguistics 25: 201-218.

Schegloff, Emanuel. 1992. Repair after next turn: the last structurally provided defense of intersubjectivity in conversation. American Journal of Sociology 97: 1295-1345.

Schegloff, Emanuel. 2001. Getting serious: joke >> serious 'no'. Journal of Pragmatics 33: 1947-1955.

Schegloff, Emanuel. 2007. Sequence Organization in Interaction. Cambridge: Cambridge University Press.

Schegloff, Emanuel, Jefferson, Gail and Sacks, Harvey. 1977. The preference for selfcorrection in the organization of repair in conversation. Language 53: 361-382.

Schegloff, Emanuel and Sacks, Harvey. 1973. Opening up closings. Semiotica 8: 289-327.

Schenkein, James N. 1972. Towards an analysis of natural conversation and the sense of heheh. Semiotica 6: 344-377.

Schnurr, Stephanie. 2010. Humour. In Locher, Miriam A. and Graham, Sage L. (eds.), Interpersonal Pragmatics. Berlin: Mouton de Gruyter, pp. 307-326.

Sherzer, Joel. 2002. Speech Play and Verbal Art. Austin, TX: University of Texas Press.

Skalicky, Stephen, Berger, Cynthia M. and Bell, Nancy. 2015. The functions of 'just kidding' in American English. Journal of Pragmatics 85: 18-31. 
Stivers, Tanya. 2008. Stance, alignment, and affiliation during storytelling: when nodding is a token of affiliation. Research on Language and Social Interaction 41: 31-57.

Straehle, Carolyn. 1993. "Samuel?” "Yes dear?” Teasing and conversational rapport. In Tannen, Deborah (ed.), Framing in Discourse. Oxford: Oxford University Press, p 210230.

Svennevig, Jan. 1999. Getting Acquainted in Conversation. Amsterdam: John Benjamins.

Vincent, Jocelyne and Castelfranchi, Cristiano. 1981. On the art of deception: How to lie while saying the truth. In Parret, Herman, Sbisà, Marina and Verschueren, Jef (eds.), Possibilities and Limitations of Pragmatics. Amsterdam: John Benjamins, pp. 749-777.

Vincent Marrelli, Jocelyne. 1994. On non-serious talk: Some cross-cultural remarks on the (un)importance of (not) being earnest. In Parret, Herman (ed.), Pretending to Communicate. Berlin: Mouton de Gruyter, pp. 253-275.

Wedgwood, Daniel. 2011. The individual in interaction: why cognitive and discourse-level pragmatics need not conflict. Intercultural Pragmatics 8: 517-542.

Wierzbicka, Anna. 2003. Cross-cultural Pragmatics: The Semantics of Human Interaction. Berlin: Mouton de Gruyter. 